\title{
The Sudden Infant Death Syndrome
}

\author{
Hannah C. Kinney, M.D. and Bradley T. Thach, M.D. \\ Department of Pathology, Children's Hospital, and Harvard Medical School - both in Boston \\ (H.C.K.); and the Department of Pediatrics, Washington University School of Medicine, St. Louis \\ (B.T.T.).
}

\begin{abstract}
The sudden infant death syndrome (sids), which is characterized by the sudden death of a seemingly healthy infant during a sleep period, has long been considered one of the most mysterious disorders in medicine. ${ }^{1,2}$ However, in recent years, SIDS has been substantially demystified by major advances in our understanding of its relationship to sleep and homeostasis, environmental and genetic risk factors, and biochemical and molecular abnormalities. The most important advance has been the discovery that the prone sleep position more than triples the risk of SIDS, ${ }^{3}$ which in the early 1990s led to national and international campaigns advocating a supine sleep position for infants. Since then, it has been estimated that rates of SIDS have declined by more than $50 \%$, and thousands of infant lives have been saved. ${ }^{3-6}$ However, SIDS still remains the leading cause of postneonatal infant death in the United States and is the third leading cause of infant mortality overall. ${ }^{7}$ This review highlights the major advances in our understanding of SIDS.
\end{abstract}

\section{DEFINITION AND INCIDENCE OF SIDS}

In 1969, a National Institutes of Health consensus conference led to the first standardized definition of sudden infant death as the "sudden death of an infant or young child, which is unexpected by history, and in which a thorough post mortem examination fails to demonstrate an adequate cause of death." 8 The definition mandated an autopsy for infants who died from a condition diagnosed as SIDS, which would demarcate a set of infants with similar characteristics for whom vital statistics, research, and family counseling were needed. Although SIDS was defined as a syndrome and thus potentially the result of more than one disease, many observers still viewed SIDS as a single entity because of its distinctive features, which included a peak incidence at 2 to 4 months of age, male predominance, and the presence of intrathoracic petechiae. Subsequent modifications of the definition restricted its application to infants under the age of 12 months, ${ }^{9}$ added the requirement of a death-scene investigation, ${ }^{9}$ or linked the death to a sleep period (i.e., the time when the majority of deaths occurred ${ }^{10}$ ). Of note, it is unclear whether SIDS occurs during sleep itself or during the many transitions between sleep and arousal that occur during the night, since such deaths are typically not witnessed. No single definition of SIDS is universally accepted, and contradictions among SIDS studies are due in part to the use of various definitions of the syndrome around the world. ${ }^{11}$

Among the industrialized nations, Japan has the lowest reported SIDS rate (0.09 case per 1000 infants), New Zealand has the highest rate (0.80 per 1000), and the United States has an intermediate rate $(0.57$ per 1000$) .{ }^{6}$ A striking discrepancy exists among racial and ethnic

Copyright () 2009 Massachusetts Medical Society. All rights reserved.

Address reprint requests to Dr. Kinney at the Department of Pathology, Enders Bldg. 1112, Children's Hospital Boston, 300 Longwood Ave., Boston, MA 02115, or at hannah.kinney@childrens.harvard.edu..

No potential conflict of interest relevant to this article was reported. 
groups that have been studied, with SIDS rates that are two to seven times the national averages among Native Americans ${ }^{12}$ and blacks ${ }^{13}$ in the United States; among persons of mixed ancestry in Cape Town, South Africa ${ }^{14}$; among Maoris in New Zealand ${ }^{4,15}$; and among aboriginal Australians. ${ }^{15}$ In a recent review of SIDS data from 13 predominantly industrialized countries, ${ }^{16}$ the majority of countries had a major decrease in SIDS rates from 1990 to 2005 (the most recent year for which data were available), with the largest decreases occurring before 2000. ${ }^{16}$ These decreases ranged from $40 \%$ in Argentina to $83 \%$ in Ireland. The true incidence of SIDS may be masked by a so-called diagnostic shift, or the use of diagnoses other than SIDS on death certificates (e.g., accidental suffocation, positional accidental asphyxia, and indeterminate cause). Diagnostic shift may explain, in part, why postneonatal death rates for both SIDS and non-SIDS have remained static since approximately $2000 .^{16-18}$

\section{CAUSES OF SUDDEN AND UNEXPECTED INFANT DEATH}

The term "sudden and unexpected infant death" (SUID) is used to describe all such deaths, regardless of cause. Cases of SUID that remain unexplained after a complete autopsy and review of the circumstances of death and clinical history are classified as SIDS. Thus, SIDS is one of the causes of SUID and accounts for $80 \%$ of such deaths. Approximately $20 \%$ of SUID cases have a clear cause, including severe, unequivocal infection. ${ }^{19}$ In the past 25 years, two causes of death have been defined in a small but important percentage of the SUID population. These are inherited disorders of fatty acid oxidation, particularly mutations in the medium-chain acyl-coenzyme A dehydrogenase (MCAD) gene ${ }^{20,21}$ (accounting for approximately $1 \%$ of SUID cases), and genetic cardiac channelopathies (accounting for 5 to $10 \%$ of SUID cases). ${ }^{22-24}$ In these disorders, metabolic or molecular testing in combination with autopsy provides the specific diagnosis. Some investigators have suggested that once a specific cause is identified, such cases should no longer be classified as either SIDS or SUID but, rather, as explained deaths. ${ }^{20}$

It is estimated that among cases of sudden infant death, the incidence of infanticide due to intentional suffocation is less than $5 \% .{ }^{25,26}$ Although intentional suffocation with a soft object (e.g., a pillow) is virtually impossible to distinguish from SIDS at autopsy, the likelihood of such a cause may be suggested by the death of an infant over the age of 6 months, a history of recurrent life-threatening events in the infant under the care of the same person, and a history of a previous death of an infant with the same caretaker. ${ }^{26}$

A causal role for mild infection in sudden infant death is suggested by reports that in approximately half of SIDS cases, the infants have a seemingly trivial infection around the time of death, as well as mild tracheobronchial inflammation and altered serum immunoglobulin or cytokine levels and the presence of microbial isolates at autopsy. ${ }^{27,28} \mathrm{In}$ infants who die unexpectedly of infection, the given organism may precipitate a lethal cytokine cascade or toxic response. ${ }^{27}$ If all specific causes of infant death are delineated, the designations SUID and SIDS will no longer be needed.

\section{NEWER MODELS FOR SIDS}

After the recognition that sleeping in the prone position was associated with SIDS, attention turned to factors that might trigger infant death in this position. Such factors include asphyxia due to airway compression or rebreathing of exhaled gases in the face-down position, impaired heat loss with subsequent hyperthermia when the face is pressed against bedding, impaired cardiorespiratory regulation related to heat stress, and compromised arousal in response to asphyxia generated in the prone position. 
One way of conceptualizing the emerging multidisciplinary data is with the Triple-Risk Model, proposed in $1994 .{ }^{29}$ Like other models, it emphasizes the interaction of multiple factors in the pathogenesis of SIDS. ${ }^{27,30}$ According to this model, SIDS occurs when three factors are present simultaneously. The first factor is an underlying vulnerability in the infant; the second, a critical developmental period; and the third, an exogenous stressor (Table 1). Exogenous stressors are considered to be homeostatic stressors, such as asphyxia. During the first year of life, rapid changes in the maturation of cardiorespiratory control and in cycling between sleeping and waking occur, first as the fetus transitions to extrauterine life and subsequently as the infant adjusts to postnatal life. ${ }^{29}$ According to the Triple-Risk Model, SIDS does not cause death in normal infants but, rather, only in vulnerable infants with an underlying abnormality. Therefore, the change to a supine sleep position is effective because once the exogenous stressor (e.g., face-down position) is removed, the vulnerable infant passes through the critical period unharmed.

However, otherwise normal infants without innate vulnerability may also die if they are caught in situations from which they cannot escape - for example, if they become wedged between the mattress and the crib railing. ${ }^{31}$ Bed sharing may involve compromise of an infant's upper airway due to close bodily contact with another person or suffocation by adult bedding, such as pillows. ${ }^{31}$ In a recent study, $85 \%$ of 209 sudden infant deaths were associated with circumstances "consistent with asphyxia," which included a prone position and bed sharing, suggesting a major role of asphyxia in the pathogenesis of sudden infant death overall. ${ }^{32}$ Careful investigation after the occurrence of sudden infant deaths has indicated that approximately $13 \%$ or more of such unexplained deaths are attributable to accidental or intentional suffocation..$^{33}$ Nevertheless, the diagnosis of asphyxia as the cause of death is subjective, since terminal blood gas levels are obviously unknown. There are no biomarkers that can be obtained posthumously that distinguish between asphyxia-related deaths in normal infants and those in vulnerable infants.

\section{RISK FACTORS FOR SIDS}

Risk factors for SIDS can be divided into extrinsic and intrinsic categories. ${ }^{34}$ Extrinsic risk factors are physical stressors that would place a vulnerable infant at risk for asphyxia or other homeostatic derangement. Such extrinsic factors include prone and side-sleeping positions, bedclothes that cover the head, sleeping on sofas or other soft furniture in which the infant could become wedged, a high ambient temperature in the sleeping environment, soft bedding, and bed sharing. $3,4,12,13,35,36$ Although the incidence of a prone sleep position is currently $20 \%$ or less, ${ }^{16,37} 30$ to $50 \%$ of infants with SIDS are still found in the prone position. ${ }^{38}$ Approximately 50\% of sudden infant deaths occur when infants are sharing a bed, sofa, or sofa chair with another person. ${ }^{13}$ The prone sleep position and a soft mattress are associated with an increase by a factor of 20 in the risk of SIDS, suggesting additive risk for these two factors. ${ }^{36}$ However, there are arguments in favor of bed sharing, which include facilitation of breast-feeding and nighttime bonding, behaviors that are beneficial to an infant's well-being. ${ }^{39}$ Approximately $10 \%$ of SIDS cases occur in infants who sleep in a supine position and do not share a bed and whose face is not covered by bedclothes. ${ }^{5}$ This finding reinforces the points that such risk factors are not causative and that the causes of SIDS are multifactorial.

In addition to extrinsic risk factors related to external events around the time of death, intrinsic factors are postulated to affect the underlying vulnerability of the infant and thus increase the risk of SIDS. Intrinsic risk factors can be subdivided into developmental factors, such as prematurity, ${ }^{40}$ and putative genetic factors, such as familial SIDS (i.e., a recurrence of SIDS in subsequent siblings), ${ }^{25,41}$ male sex (by a 2:1 ratio), and race or ethnic group. ${ }^{13}$ 
Certain genetic polymorphisms have been associated with SIDS..$^{20,25,42,43}$ During the past two decades, the search for SIDS susceptibility genes has focused on the hypothesis that SIDS is a homeostatic disorder, and polymorphisms associated with SIDS have been reported in a variety of genes involved in autonomic function, neurotransmission, energy metabolism, and response to infection..$^{25,42,43}$ In addition, the vulnerable infant's response to environmental factors may actually reflect aberrant intrinsic responses. For that reason, events and environmental conditions extrinsic to the infant, such as poverty, $5,15,44,45$ adverse prenatal exposures to certain substances (e.g., cigarette smoke and alcohol or illicit drugs), ${ }^{6,12,46,47}$ and postnatal exposure to cigarette smoke, may trigger intrinsic responses in the vulnerable infant. For example, prenatal exposures to alcohol and cigarette smoke have a direct effect on neurotransmitter systems that are critical to homeostatic control in the developing human brain. ${ }^{48}$

Given the change in the demographic characteristics associated with SIDS, infants who die of SIDS in the present era may differ from those who died in previous eras. In the United Kingdom, for example, the proportion of SIDS deaths occurring in term infants has decreased, whereas the proportion in preterm infants has increased from $12 \%$ to $34 \%$ $(\mathrm{P}<0.001) .{ }^{46}$ Furthermore, the proportion of SIDS deaths occurring in families living in poverty has increased from $47 \%$ to $74 \%(\mathrm{P}=0.003)$, and the proportion of SIDS deaths in infants of mothers who smoked during pregnancy has increased from $57 \%$ to $87 \%$ ( $\mathrm{P}=$ $0.004) .46$

The delineation of risk factors has been crucial for establishing the biologic basis of disparities in the incidence of SIDS among racial and ethnic groups. ${ }^{12,13,49}$ Although high SIDS rates among American blacks and Native Americans, Maoris, and aboriginal Australians may reflect factors that are independent of economic levels, poverty is associated with higher rates of maternal alcohol use and smoking during pregnancy, of prematurity, and of bed sharing (due to a lack of space and funds for cribs). ${ }^{12,16,49}$ Adding to the concern is evidence that recommendations for preventing SIDS are not reaching highrisk communities. ${ }^{13,15,37}$ Efforts are under way to understand the barriers to the promulgation of prevention messages and to optimize such recommendations in high-risk populations. $., 13,50$

\section{PUTATIVE TERMINAL PATHWAYS FOR SIDS}

A key question in SIDS research remains: How do infants die of SIDS? Although multiple theories have been advanced about the mechanism of death in SIDS, the cardiorespiratorycontrol hypothesis has dominated the research. In a 1982 review, Shannon and Kelly stated that "sudden death without an obvious cause implies the cessation of autonomic regulation of cardiovascular or respiratory activity or both." In the ensuing years, all SIDS hypotheses essentially invoked defective respiratory or autonomic mechanisms. ${ }^{27,30,51-58}$ The roles of respiratory and autonomic pathways in SIDS are not mutually exclusive, given that infants who subsequently died of SIDS have frequently been found to have subclinical deficits in both respiratory and autonomic function. ${ }^{59-61}$ Ultimately, SIDS appears to involve failed defense mechanisms, with sleep in some important way unmasking the underlying vulnerability.

Clinical observations in infants, analysis of heart-rate and respiration recordings in infants who subsequently died of SIDS, and physiological studies in animal models provide compelling evidence for a respiratory pathway in the majority of SIDS deaths (Fig. 1). For purposes of clarity, the respiratory pathway to SIDS can be divided into five steps. First, a life-threatening event (which may occur in any infant during sleep) causes severe asphyxia, brain hypoperfusion, or both. Such life-threatening events include rebreathing of exhaled 
gases in the face-down position ${ }^{62}$ or in the face-covered (supine) position, ${ }^{63}$ reflex apnea originating from the laryngeal chemoreflex, ${ }^{64}$ and obstructive apnea due to gastric regurgitation. The laryngeal chemoreflex consists of reflex apnea and swallowing in response to the activation of receptors in the laryngeal lumen by water or gastric contents; it occurs early in life and disappears thereafter, although the precise time in infancy is unknown. ${ }^{64,65}$ Second, the vulnerable infant does not wake up and turn his or her head in response to asphyxia (combined hypoxia and hypercapnia), resulting in rebreathing or an inability to recover from apnea. Third, progressive asphyxia leads to a loss of consciousness and areflexia, a so-called hypoxic coma, a step that is hypothesized to occur on the basis of extrapolations from studies in animals that indicate the rapid development of coma when a critical level of the partial pressure of arterial oxygen is reached (approximately $10 \mathrm{~mm} \mathrm{Hg}$ ) or when hypoperfusion results in extreme brain hypoxia. ${ }^{66}$ Fourth, extreme bradycardia and hypoxic gasping ensue, changes that are evident in the terminal-event recordings in infants who were being monitored at home at the time of death from $\operatorname{SIDS}^{67,68}$ (Fig. 2). Fifth, in the vulnerable infant, autoresuscitation is impaired - a second defense failure - because of ineffectual gasping, which results in uninterrupted apnea and death. ${ }^{67,68}$ Recordings in the same infants over time indicate that SIDS is not always a "sudden" disorder; rather, death may be preceded by a vicious cycle of episodic tachycardia, bradycardia, or apnea hours and even days before the lethal event. Evidence of intermittent hypoxia in infants with SIDS includes markers of chronic tissue hypoxia, ${ }^{69-71}$ such as brain-stem gliosis and apoptosis. ${ }^{72-74}$

Arousal from sleep that is triggered by abnormal levels of carbon dioxide and oxygen is essential for the initiation of protective airway responses; indeed, head turning and escape to fresh air are critical for survival from an asphyxial microenvironment. ${ }^{75}$ Arousal involves a progressive activation of specific subcortical-to-cortical brain structures and consists of ascending and descending components that mediate cortical and subcortical arousal, respectively, with feedback loops between them. Cortical arousal involves noradrenergic, serotonergic (5-hydroxytryptamine), dopaminergic, cholinergic, and histaminergic neurons in the brain stem, basal forebrain, and hypothalamus, which excite the cerebral cortex and cause cortical activation. ${ }^{76}$ Subcortical arousal, on the other hand, is mediated mainly by brain-stem pathways that increase the heart rate, blood pressure, respiration, and postural tone without changes in cortical activity. ${ }^{77}$ In a prospective study of infants who subsequently died of SIDS, the infants had more frequent and longer episodes of subcortical arousal but fewer episodes of cortical arousal than did control infants, findings that are indicative of subclinical arousal deficits. ${ }^{78}$ Other prospective studies support the presence of arousal deficits in infants with SIDS. ${ }^{79,80}$

In severe hypoxia or ischemia, normal breathing fails and is replaced by gasping. ${ }^{81}$ Gasping increases the volume of air in the lungs, followed by oxygen transport to the heart, increased cardiac output, and finally brain perfusion and reoxygenation. The act of gasping involves neurons within the rostral medulla that demonstrate a "bursting" discharge due to pacemaker activity and that are modulated by 5-hydroxytryptamine and norepinephrine, which in combination sustain gasping and restore rhythmic respiratory activity. ${ }^{81-83}$ Tracings from infants who subsequently died of SIDS have indicated that their gasping was ineffectual, with large-amplitude breaths, abnormally complex gasps, and an inability to increase the heart rate (Fig. 2). ${ }^{6}$ Some infants with acute life-threatening events (characterized by apnea and unresponsiveness that is interrupted by resuscitation, with no underlying disorder diagnosed) may represent potential SIDS cases in which the failure in gasping is averted by successful intervention. The incidence of acute, life-threatening events is significantly increased in infants with SIDS (12\%, vs. $3 \%$ in control infants). ${ }^{84}$ 
Cardiorespiratory recordings from infants who subsequently died of SIDS have shown episodes of tachycardia and bradycardia hours or days before death, 68,85 suggesting a primary failure of autonomic mechanisms. Thus, one pathway for SIDS may involve inadequate compensatory autonomic responses to a hypotensive challenge that results from a cardiac arrhythmia, a "shock-like" sequence, ${ }^{52}$ or respiratory perturbation with secondary hypotension. Although a role for abnormal thermoregulation in SIDS is controversial, ${ }^{58}$ such a mechanism is suggested by reports of increased risk associated with heavy wrapping and elevated room temperatures at the time of death. ${ }^{55}$ Since the face is an important source of heat elimination in infants, ${ }^{55,86}$ SIDS infants who are found face-down in bedclothing may have died from heat stress, which causes lethal respiratory inhibition or bradycardia without necessarily elevating the body temperature.

The biologic role of SIDS risk factors becomes comprehensible in light of the abovementioned pathways, since many risk factors can trigger asphyxia or other homeostatic stressors and exacerbate the underlying vulnerability. An increased risk of SIDS in the first 6 months of life probably reflects a convergence of immature homeostatic systems. ${ }^{87-89}$ Premature infants may be at greater risk than term infants because they appear to have fewer and shorter arousal episodes and immature cardiorespiratory patterning. ${ }^{88,89}$ The prone sleep position increases the likelihood of re-breathing in the face-down position, upper-airway obstruction, and hyperthermia. ${ }^{36,90}$ Developmental motor mechanisms also may underlie the risk associated with a prone sleep position, since all newborns obviously lack experience in sleeping in this position. Furthermore, infants have not fully learned the efficient protective strategies of head lifting and turning. ${ }^{58,91}$ Conceivably, developmental deficits in neural pathways that support reflexive motor learning may increase the risk associated with sleeping in the prone position. In addition, the prone sleep position is associated with impaired arousal from sleep, reduced vasomotor tone, and diminished laryngeal chemoreflexes and baroreceptor reflexes. ${ }^{92-95}$ Infants who were exposed to maternal smoking during gestation have reductions in the frequency of arousal from sleep. ${ }^{96}$

\section{ASPHYXIA-RELATED SUDDEN DEATHS}

The search for the underlying vulnerability in SIDS infants has led to intense analysis of peripheral and central sites critical to protective responses to asphyxia and hypoxia. The major focus of SIDS research has been on the brain stem because it contains critical neural networks that mediate respiration, chemosensitivity, autonomic function, sleep, and arousal $^{53,57}$ (Fig. 3). Abnormalities in various neurotransmitters or their receptors have now been reported in relevant brainstem regions in infants with SIDS. ${ }^{97}$ To date, the most robust evidence for a neurochemical abnormality comes from research on the medullary 5hydroxytryptamine system, in that approximately 50 to $75 \%$ of infants with SIDS appear to have abnormalities in this system. ${ }^{34,98-100}$ The medullary 5-hydroxytryptamine system, which is considered critical for the modulation and integration of diverse homeostatic functions, according to the level of arousal, ${ }^{101}$ is involved in ventilation and gasping, $, 22,83,102$ thermoregulation, autonomic control, ${ }^{103}$ responses to carbon dioxide ${ }^{104}$ and oxygen, ${ }^{105}$ arousal from sleep, ${ }^{106}$ and hypoxia-induced plasticity. ${ }^{107}$ Abnormalities in 5-hydroxytryptamine neuronal number and differentiation, receptors, or transporter have been reported in the medulla of infants with SIDS, as compared with control infants, in four independent data sets. ${ }^{34,98-100}$ Given the wide array of homeostatic functions modulated by the medullary 5-hydroxytryptamine system, sudden death may result from a convergence of defects in protective responses to homeostatic stressors during sleep that are modulated by 5-hydroxytryptamine, probably in conjunction with related neurotransmitters. 


\section{RECOMMENDATIONS FOR RISK REDUCTION AND COUNSELING}

Risk-reduction recommendations include putting infants to bed in the supine position on a firm mattress, preferably with a pacifier (mechanism unknown) and in a shared room (but in a separate bed). ${ }^{6,108}$ Prone and side sleeping, overheating, bed sharing, soft bedding, and smoking by mothers during pregnancy or around infants should be avoided. ${ }^{6,108}$ Home cardiorespiratory monitoring of apnea and bradycardia is not recommended because it has not been shown to prevent SIDS. ${ }^{87,109}$ However, efforts are under way to develop more sophisticated and sensitive measures of the putative subclinical cardiorespiratory deficits in infants who are at risk for SIDS. ${ }^{56,59}$

Grief counseling for families that have lost an infant to SIDS is especially challenging in light of the sudden and unwitnessed nature of the infant's death, the lack of a universally accepted biologic explanation for the death, and possible suspicion by others of foul play. However, important counseling strategies for families with infants who have died of SIDS have been devised. ${ }^{110}$ Of major concern in such families is the risk of SIDS in subsequent siblings. Although in such cases there is an increase in risk, it is minimal. For example, with an assumed incidence of 0.7 case per 1000 for the first infant and a relative risk of recurrence in a sibling of 5 , it would be estimated that $99.6 \%$ of subsequent siblings would survive infancy. 25

\section{CONCLUSIONS}

Current evidence suggests that SIDS involves a convergence of stressors that probably results in the asphyxia of a vulnerable infant who has defective cardiorespiratory or arousal defense systems during a critical developmental period when immature defense mechanisms are not fully integrated. Thus, our current understanding of the pathogenesis of SIDS reflects the simultaneous juxtaposition of multiple events that, when taken individually, are far less powerful than the result of their chance combination. SIDS remains a major problem that mandates continued interdisciplinary efforts for its ultimate resolution.

\section{Acknowledgments}

Supported by grants from the National Institute of Child Health and Human Development (R37-HD20991 and PO1-HD036379, to Dr. Kinney; and RO1-HD10993, to Dr. Thach), by the First Candle/SIDS Alliance, the CJ Foundation for SIDS, the C.J. Murphy Foundation, the Deborah Evelyn Barrett Fellowship, and the Scottish Cot Death Trust and by a grant from the Children's Hospital Developmental Disabilities Research Center (P30HD18655).

We thank Richard A. Belliveau, Kristin McMillan, and Kathleen Harris for their assistance in the preparation of the manuscript and Drs. Holcombe E. Grier, Joseph J. Volpe, and Eugene E. Nattie for their many helpful comments.

\section{REFERENCES}

1. Shannon DC, Kelly DH. SIDS and near-SIDS (second of two parts). N Engl J Med. 1982; 306:1022-8. [PubMed: 7038502]

2. Shannon DC, Kelly DH. SIDS and near-SIDS (first of two parts). N Engl J Med. 1982; 306:959-65. [PubMed: 7038498]

3. Willinger M, Hoffman HJ, Hartford RB. Infant sleep position and risk for sudden infant death syndrome: report of meeting held January 13 and 14, 1994, National Institutes of Health, Bethesda, MD. Pediatrics. 1994; 93:814-9. [PubMed: 8165085]

4. Mitchell EA, Brunt JM, Everard C. Reduction in mortality from sudden infant death syndrome in New Zealand: 1986-92. Arch Dis Child. 1994; 70:291-4. [PubMed: 8185361]

5. Beal SM. Sudden infant death syndrome in South Australia 1968-97. Part I: changes over time. J Paediatr Child Health. 2000; 36:540-7. [PubMed: 11115028] 
6. Moon RY, Horne RS, Hauck FR. Sudden infant death syndrome. Lancet. 2007; 370:1578-87. [PubMed: 17980736]

7. Hoyert DL. Mortality associated with birth defects: influence of successive disease classification revisions. Birth Defects Res A Clin Mol Teratol. 2003; 67:651-5. [PubMed: 14703789]

8. Beckwith, JB. Discussion of the terminology and definition of the sudden infant death syndrome.. In: Bergman, AB.; Beckwith, JB.; Ray, CG., editors. Proceedings of the Second International Conference on Causes of Sudden Death in Infants. University of Washington Press; Seattle: 1970. p. 14-22.

9. Willinger M, James LS, Catz C. Defining the sudden infant death syndrome (SIDS): deliberations of an expert panel convened by the National Institute of Child Health and Human Development. Pediatr Pathol. 1991; 11:677-84. [PubMed: 1745639]

10. Krous HF, Beckwith JB, Byard RW, et al. Sudden infant death syndrome and unclassified sudden infant deaths: a definitional and diagnostic approach. Pediatrics. 2004; 114:234-8. [PubMed: 15231934]

11. Byard RW, Marshall D. An audit of the use of definitions of sudden infant death syndrome (SIDS). J Forensic Leg Med. 2007; 14:453-5. [PubMed: 17961869]

12. Iyasu S, Randall LL, Welty TK, et al. Risk factors for sudden infant death syndrome among Northern Plains Indians. JAMA. 2002; 288:2717-23. [Erratum, JAMA 2003;289:303.]. [PubMed: 12460095]

13. Hauck FR, Herman SM, Donovan M, et al. Sleep environment and the risk of sudden infant death syndrome in an urban population: the Chicago Infant Mortality Study. Pediatrics. 2003; 111:120714. [PubMed: 12728140]

14. Molteno CD, Ress E, Kibel MA. Early childhood mortality in Cape Town. S Afr Med J. 1989; 75:570-4. [PubMed: 2727857]

15. Ford RP, Nelson KP. Higher rates of SIDS persist in low income groups. J Paediatr Child Health. 1995; 31:408-11. [PubMed: 8554860]

16. Hauck FR, Tanabe KO. International trends in sudden infant death syndrome: stabilization of rates requires further action. Pediatrics. 2008; 122:660-6. [PubMed: 18762537]

17. Shapiro-Mendoza CK, Tomashek KM, Anderson RN, Wingo J. Recent national trends in sudden, unexpected infant deaths: more evidence supporting a change in classification or reporting. Am J Epidemiol. 2006; 163:762-9. [PubMed: 16582034]

18. Malloy MH, MacDorman M. Changes in the classification of sudden unexpected infant deaths: United States, 1992-2001. Pediatrics. 2005; 115:1247-53. [PubMed: 15867031]

19. Vennemann M, Bajanowski T, Butterfass-Bahloul T, et al. Do risk factors differ between explained sudden unexpected death in infancy and sudden infant death syndrome? Arch Dis Child. 2007; 92:133-6. [PubMed: 16935913]

20. Opdal SH, Rognum TO. The sudden infant death syndrome gene: does it exist? Pediatrics. 2004; 114(4):e506-e512. [PubMed: 15466077]

21. Bennett MJ, Powell S. Metabolic disease and sudden, unexpected death in infancy. Hum Pathol. 1994; 25:742-6. [PubMed: 8056419]

22. Schwartz PJ, Stramba-Badiale M, Segantini A, et al. Prolongation of the QT interval and the sudden infant death syndrome. N Engl J Med. 1998; 338:1709-14. [PubMed: 9624190]

23. Ackerman MJ, Siu BL, Sturner WQ, et al. Postmortem molecular analysis of SCN5A defects in sudden infant death syndrome. JAMA. 2001; 286:2264-9. [PubMed: 11710892]

24. Arnestad M, Crotti L, Rognum TO, et al. Prevalence of long-QT syndrome gene variants in sudden infant death syndrome. Circulation. 2007; 115:361-7. [PubMed: 17210839]

25. Hunt CE. Sudden infant death syndrome and other causes of infant mortality: diagnosis, mechanisms, and risk for recurrence in siblings. Am J Respir Crit Care Med. 2001; 164:346-57. [PubMed: 11500332]

26. American Academy of Pediatrics; Hymel KP, Committee on Child Abuse and Neglect, National Association of Medical Examiners. Distinguishing sudden infant death syndrome from child abuse fatalities. Pediatrics. 2006; 118:421-7. [PubMed: 16818592]

27. Vege A, Ole Rognum T. Sudden infant death syndrome, infection and inflammatory responses. FEMS Immunol Med Microbiol. 2004; 42:3-10. [PubMed: 15325392] 
28. Weber MA, Klein NJ, Hartley JC, Lock PE, Malone M, Sebire NJ. Infection and sudden unexpected death in infancy: a systematic retrospective case review. Lancet. 2008; 371:1848-53. [PubMed: 18514728]

29. Filiano JJ, Kinney HC. A perspective on neuropathologic findings in victims of the sudden infant death syndrome: the triple-risk model. Biol Neonate. 1994; 65:194-7. [PubMed: 8038282]

30. Guntheroth WG, Spiers PS. The triple risk hypotheses in sudden infant death syndrome. Pediatrics. 2002; 110(5):e64. [PubMed: 12415070]

31. Byard RW. Hazardous infant and early childhood sleeping environments and death scene examination. J Clin Forensic Med. 1996; 3:115-22. [PubMed: 15335607]

32. Pasquale-Styles MA, Tackitt PL, Schmidt CJ. Infant death scene investigation and the assessment of potential risk factors for asphyxia: a review of 209 sudden unexpected infant deaths. J Forensic Sci. 2007; 52:924-9. [PubMed: 17553088]

33. Moore BM, Fernbach KL, Finkelstein MJ, Carolan PL. Impact of changes in infant death classification on the diagnosis of sudden infant death syndrome. Clin Pediatr (Phila). 2008; 47:770-6. [PubMed: 18448626]

34. Paterson DS, Trachtenberg FL, Thompson EG, et al. Multiple serotonergic brainstem abnormalities in sudden infant death syndrome. JAMA. 2006; 296:2124-32. [PubMed: 17077377]

35. Kemp JS, Unger B, Wilkins D, et al. Unsafe sleep practices and an analysis of bedsharing among infants dying suddenly and unexpectedly: results of a four-year, population-based, death-scene investigation study of sudden infant death syndrome and related deaths. Pediatrics. 2000; 106(3):E41. [PubMed: 10969125]

36. Ponsonby AL, Dwyer T, Gibbons LE, Cochrane JA, Wang YG. Factors potentiating the risk of sudden infant death syndrome associated with the prone position. N Engl J Med. 1993; 329:37782. [PubMed: 8326970]

37. Corwin MJ, Lesko SM, Heeren T, et al. Secular changes in sleep position during infancy: 1995-1998. Pediatrics. 2003; 111:52-60. [PubMed: 12509554]

38. Mitchell EA, Bajanowski T, Brinkmann B, Jorch G, Stewart AW, Vennemann MM. Prone sleeping position increases the risk of SIDS in the day more than at night. Acta Paediatr. 2008; 97:584-9. [PubMed: 18373718]

39. McKenna JJ, Ball HL, Gettler LT. Mother-infant cosleeping, breastfeeding and sudden infant death syndrome: what biological anthropology has discovered about normal infant sleep and pediatric sleep medicine. Am J Phys Anthropol. 2007; (Suppl 45):133-61. [PubMed: 18046747]

40. Horne RS. Effects of prematurity on heart rate control: implications for sudden infant death syndrome. Expert Rev Cardiovasc Ther. 2006; 4:335-43. [PubMed: 16716094]

41. Oyen N, Skjaerven R, Irgens LM. Population-based recurrence risk of sudden infant death syndrome compared with other infant and fetal deaths. Am J Epidemiol. 1996; 144:300-5. [PubMed: 8686699]

42. Weese-Mayer DE, Ackerman MJ, Marazita ML, Berry-Kravis EM. Sudden infant death syndrome: review of implicated genetic factors. Am J Med Genet A. 2007; 143:771-88. [PubMed: 17340630]

43. Hunt CE. Gene-environment interactions: implications for sudden unexpected deaths in infancy. Arch Dis Child. 2005; 90:48-53. [PubMed: 15613511]

44. Blair PS, Platt MW, Smith IJ, Fleming PJ. Sudden infant death syndrome and sleeping position in pre-term and low birth weight infants: an opportunity for targeted intervention. Arch Dis Child. 2006; 91:101-6. [PubMed: 15914498]

45. Malloy MH, Hoffman HJ. Prematurity, sudden infant death syndrome, and age of death. Pediatrics. 1995; 96:464-71. [PubMed: 7651779]

46. Blair PS, Sidebotham P, Berry PJ, Evans M, Fleming PJ. Major epidemiological changes in sudden infant death syndrome: a 20-year population-based study in the UK. Lancet. 2006; 367:314-9. [PubMed: 16443038]

47. Blair PS, Fleming PJ, Bensley D, et al. Smoking and the sudden infant death syndrome: results from 1993-5 case-control study for confidential inquiry into stillbirths and deaths in infancy. BMJ. 1996; 313:195-8. [PubMed: 8696194]

48. Duncan JR, Randall LL, Belliveau RA, et al. The effect of maternal smoking and drinking during pregnancy upon (3)H-nicotine receptor brainstem binding in infants dying of the sudden infant 
death syndrome: initial observations in a high risk population. Brain Pathol. 2008; 18:21-31. [PubMed: 17924983]

49. Mitchell EA, Thompson JM, Stewart AW, et al. Postnatal depression and SIDS: a prospective study. J Paediatr Child Health. 1992; 28(Suppl 1):S13-S16. [PubMed: 1524875]

50. Colson ER, Levenson S, Rybin D, et al. Barriers to following the supine sleep recommendation among mothers at four centers for the Women, Infants, and Children Program. Pediatrics. 2006; 118:e243-50. [PubMed: 16882769]

51. Leiter JC, Bohm I. Mechanisms of pathogenesis in the sudden infant death syndrome. Respir Physiol Neurobiol. 2007; 159:127-38. [PubMed: 17644048]

52. Harper RM. Autonomic control during sleep and risk for sudden death in infancy. Arch Ital Biol. 2001; 139:185-94. [PubMed: 11330200]

53. Hunt CE, Brouillette RT. Sudden infant death syndrome: 1987 perspective. J Pediatr. 1987; 110:669-78. [PubMed: 3553512]

54. Raza MW, Blackwell CC. Sudden infant death syndrome, virus infections and cytokines. FEMS Immunol Med Microbiol. 1999; 25:85-96. [PubMed: 10443495]

55. Flemlng PJ, Azaz Y, Wigfield R. Development of thermoregulation in infancy: possible implications for SIDS. J Clin Pathol. 1992; 45(Suppl):17-9. [PubMed: 1474152]

56. Sahni R, Fifer WP, Myers MM. Identifying infants at risk for sudden infant death syndrome. Curr Opin Pediatr. 2007; 19:145-9. [PubMed: 17496756]

57. Kinney HC, Filiano JJ, White WF. Medullary serotonergic network deficiency in the sudden infant death syndrome: review of a 15-year study of a single dataset. J Neuropathol Exp Neurol. 2001; 60:228-47. [PubMed: 11245208]

58. Thach B. Tragic and sudden death: potential and proven mechanisms causing sudden infant death syndrome. EMBO Rep. 2008; 9:114-8. [PubMed: 18246101]

59. Kinney HC, Myers MM, Belliveau RA, et al. Subtle autonomic and respiratory dysfunction in sudden infant death syndrome associated with serotonergic brainstem abnormalities: a case report. J Neuropathol Exp Neurol. 2005; 64:689-94. [PubMed: 16106217]

60. Schechtman VL, Lee MY, Wilson AJ, Harper RM. Dynamics of respiratory patterning in normal infants and infants who subsequently died of the sudden infant death syndrome. Pediatr Res. 1996; 40:571-7. [PubMed: 8888285]

61. Southall DP, Stevens V, Franks CI, Newcombe RG, Shinebourne EA, Wilson AJ. Sinus tachycardia in term infants preceding sudden infant death. Eur J Pediatr. 1988; 147:74-8. [PubMed: 3338482]

62. Kemp JS, Thach BT. Sudden death in infants sleeping on polystyrene-filled cushions. N Engl J Med. 1991; 324:1858-64. [PubMed: 2041551]

63. Skadberg BT, Markestad T. Consequences of getting the head covered during sleep in infancy. Pediatrics. 1997; 100(2):E6. [PubMed: 9233977]

64. Downing SE, Lee JC. Laryngeal chemosensitivity: a possible mechanism for sudden infant death. Pediatrics. 1975; 55:640-9. [PubMed: 236536]

65. Thach BT. Sudden infant death syndrome: can gastroesophageal reflux cause sudden infant death? Am J Med. 2000; 108(Suppl 4a):144S-148S. [PubMed: 10718468]

66. Thach BT, Lijowska A. Arousals in infants. Sleep. 1996; 19(Suppl):S271-S273. [PubMed: 9085529]

67. Poets CF. Apparent life-threatening events and sudden infant death on a monitor. Paediatr Respir Rev. 2004; 5(Suppl A):S383-S386. [PubMed: 14980301]

68. Sridhar R, Thach BT, Kelly DH, Henslee JA. Characterization of successful and failed autoresuscitation in human infants, including those dying of SIDS. Pediatr Pulmonol. 2003; 36:113-22. [PubMed: 12833490]

69. Cutz E, Perrin DG, Pan J, Haas EA, Krous HF. Pulmonary neuroendocrine cells and neuroepithelial bodies in sudden infant death syndrome: potential markers of airway chemoreceptor dysfunction. Pediatr Dev Pathol. 2007; 10:106-16. [PubMed: 17378691]

70. Vege A, Chen Y, Opdal SH, Saugstad OD, Rognum TO. Vitreous humor hypoxanthine levels in SIDS and infectious death. Acta Paediatr. 1994; 83:634-9. [PubMed: 7919762] 
71. Jones KL, Krous HF, Nadeau J, Blackbourne B, Zielke HR, Gozal D. Vascular endothelial growth factor in the cerebrospinal fluid of infants who died of sudden infant death syndrome: evidence for antecedent hypoxia. Pediatrics. 2003; 111:358-63. [PubMed: 12563064]

72. Kinney HC, Burger PC, Harrell FE Jr, Hudson RP Jr. 'Reactive gliosis' in the medulla oblongata of victims of the sudden infant death syndrome. Pediatrics. 1983; 72:181-7. [PubMed: 6866602]

73. Naeye RL. Brain-stem and adrenal abnormalities in the sudden-infant-death syndrome. Am J Clin Pathol. 1976; 66:526-30. [PubMed: 961631]

74. Machaalani R, Waters KA. Neuronal cell death in the sudden infant death syndrome brainstem and associations with risk factors. Brain. 2008; 131:218-28. [PubMed: 18084013]

75. Patel AL, Harris K, Thach BT. Inspired $\mathrm{CO}(2)$ and $\mathrm{O}(2)$ in sleeping infants re-breathing from bedding: relevance for sudden infant death syndrome. J Appl Physiol. 2001; 91:2537-45. [PubMed: 11717216]

76. Sinton CM, McCarley RW. Neurophysiological mechanisms of sleep and wakefulness: a question of balance. Semin Neurol. 2004; 24:211-23. [PubMed: 15449215]

77. Lijowska AS, Reed NW, Chiodini BA, Thach BT. Sequential arousal and airway-defensive behavior of infants in asphyxial sleep environments. J Appl Physiol. 1997; 83:219-28. [PubMed: 9216967]

78. Kato I, Franco P, Groswasser J, et al. Incomplete arousal processes in infants who were victims of sudden death. Am J Respir Crit Care Med. 2003; 168:1298-303. [PubMed: 12917226]

79. Schechtman VL, Harper RM, Wilson AJ, Southall DP. Sleep state organization in normal infants and victims of the sudden infant death syndrome. Pediatrics. 1992; 89:865-70. [PubMed: 1579396]

80. Kahn A, Groswasser J, Rebuffat E, et al. Sleep and cardiorespiratory characteristics of infant victim of sudden death: a prospective case-control study. Sleep. 1992; 15:287-92. [PubMed: 1519001]

81. Paton JF, Abdala AP, Koizumi H, Smith JC, St-John WM. Respiratory rhythm generation during gasping depends on persistent sodium current. Nat Neurosci. 2006; 9:311-3. [PubMed: 16474390]

82. Tryba AK, Peña F, Ramirez JM. Gasping activity in vitro: a rhythm dependent on 5-HT2A receptors. J Neurosci. 2006; 26:2623-34. [PubMed: 16525041]

83. St-John WM, Leiter JC. Maintenance of gasping and restoration of eupnea after hypoxia is impaired following blockers of alpha1-adrenergic receptors and serotonin 5-HT2 receptors. J Appl Physiol. 2008; 104:665-73. [PubMed: 18162482]

84. Platt MW, Blair PS, Fleming PJ, et al. A clinical comparison of SIDS and explained sudden infant deaths: how healthy and how normal? Arch Dis Child. 2000; 82:98-106. [PubMed: 10648361]

85. Poets CF, Meny RG, Chobanian MR, Bonofiglo RE. Gasping and other cardiorespiratory patterns during sudden infant deaths. Pediatr Res. 1999; 45:350-4. [PubMed: 10088653]

86. Jardine DS, Haschke RH. An animal model of life-threatening hyperthermia during infancy. J Appl Physiol. 1992; 73:340-5. [PubMed: 1506389]

87. Ramanathan R, Corwin MJ, Hunt CE, et al. Cardiorespiratory events recorded on home monitors: comparison of healthy infants with those at increased risk for SIDS. JAMA. 2001; 285:2199-207. [PubMed: 11325321]

88. Scher MS, Steppe DA, Dokianakis SG, Sun M, Guthrie RD, Sclabassi RJ. Cardiorespiratory behavior during sleep in fullterm and preterm neonates at comparable postconceptional term ages. Pediatr Res. 1994; 36:738-44. [PubMed: 7898983]

89. Fifer WP, Myers MM, Sahni R, et al. Interactions between sleeping position and feeding on cardiorespiratory activity in preterm infants. Dev Psychobiol. 2005; 47:288-96. [PubMed: 16252285]

90. Fleming PJ, Gilbert R, Azaz Y, et al. Interaction between bedding and sleeping position in the sudden infant death syndrome: a population based case-control study. BMJ. 1990; 301:85-9. [PubMed: 2390588]

91. Thach WT. Combination, complementarity and automatic control: a role for the cerebellum in learning movement coordination. Novartis Found Symp. 1998; 218:219-28. [PubMed: 9949823]

92. Horne RS, Ferens D, Watts AM, et al. The prone sleeping position impairs arousability in term infants. J Pediatr. 2001; 138:811-6. [PubMed: 11391321] 
93. Ariagno RL, van Liempt S, Mirmiran M. Fewer spontaneous arousals during prone sleep in preterm infants at 1 and 3 months corrected age. J Perinatol. 2006; 26:306-12. [PubMed: 16572196]

94. Chong A, Murphy N, Matthews T. Effect of prone sleeping on circulatory control in infants. Arch Dis Child. 2000; 82:253-6. [PubMed: 10685934]

95. Galland BC, Taylor BJ, Bolton DP. Prone versus supine sleep position: a review of the physiological studies in SIDS research. J Paediatr Child Health. 2002; 38:332-8. [PubMed: 12173990]

96. Horne RS, Ferens D, Watts AM, et al. Effects of maternal tobacco smoking, sleeping position, and sleep state on arousal in healthy term infants. Arch Dis Child Fetal Neonatal Ed. 2002; 87:F100F105. [PubMed: 12193515]

97. Kinney, H.; Paterson, DS. The sudden infant death syndrome.. In: Golden, JA.; Harding, BN., editors. Pathology and genetics: acquired and inherited diseases of the developing nervous system. ISN Neuropathology Press; Basel, Switzerland: 2004. p. 194-203.

98. Panigrahy A, Filiano J, Sleeper LA, et al. Decreased serotonergic receptor binding in rhombic lipderived regions of the medulla oblongata in the sudden infant death syndrome. J Neuropathol Exp Neurol. 2000; 59:377-84. [PubMed: 10888367]

99. Kinney HC, Randall LL, Sleeper LA, et al. Serotonergic brainstem abnormalities in Northern Plains Indians with the sudden infant death syndrome. J Neuropathol Exp Neurol. 2003; 62:117891. [PubMed: 14656075]

100. Ozawa Y, Okado N. Alteration of serotonergic receptors in the brain stems of human patients with respiratory disorders. Neuropediatrics. 2002; 33:142-9. [PubMed: 12200744]

101. Lovick TA. The medullary raphe nuclei: a system for integration and gain control in autonomic and somatomotor responsiveness? Exp Physiol. 1997; 82:31-41. [PubMed: 9023504]

102. Hilaire G, Morin D, Lajard AM, Monteau R. Changes in serotonin metabolism may elicit obstructive apnoea in the newborn rat. J Physiol. 1993; 466:367-81. [PubMed: 7692042]

103. Audero E, Coppi E, Mlinar B, et al. Sporadic autonomic dysregulation and death associated with excessive serotonin autoinhibition. Science. 2008; 321:130-3. [PubMed: 18599790]

104. Bradley SR, Pieribone VA, Wang W, Severson CA, Jacobs RA, Richerson GB. Chemosensitive serotonergic neurons are closely associated with large medullary arteries. Nat Neurosci. 2002; 5:401-2. [PubMed: 11967547]

105. Penatti EM, Berniker AV, Kereshi B, et al. Ventilatory response to hypercapnia and hypoxia after extensive lesion of medullary serotonergic neurons in newborn conscious piglets. J Appl Physiol. 2006; 101:1177-88. [PubMed: 16763104]

106. Darnall RA, Harris MB, Gill WH, Hoffman JM, Brown JW, Niblock MM. Inhibition of serotonergic neurons in the nucleus paragigantocellularis lateralis fragments sleep and decreases rapid eye movement sleep in the piglet: implications for sudden infant death syndrome. J Neurosci. 2005; 25:8322-32. [PubMed: 16148240]

107. Feldman JL, Mitchell GS, Nattie EE. Breathing: rhythmicity, plasticity, chemosensitivity. Annu Rev Neurosci. 2003; 26:239-66. [PubMed: 12598679]

108. American Academy of Pediatrics Task Force on Sudden Infant Death Syndrome. The changing concept of sudden infant death syndrome: diagnostic coding shifts, controversies regarding the sleeping environment, and new variables to consider in reducing risk. Pediatrics. 2005; 116:1245-55. [PubMed: 16216901]

109. Committee on Fetus and Newborn, American Academy of Pediatrics. Apnea, sudden infant death syndrome, and home monitoring. Pediatrics. 2003; 111:914-7. [PubMed: 12671135]

110. Mandell F, McClain M. Supporting the SIDS family. Pediatrician. 1988; 15:179-82. [PubMed: 3068657] 


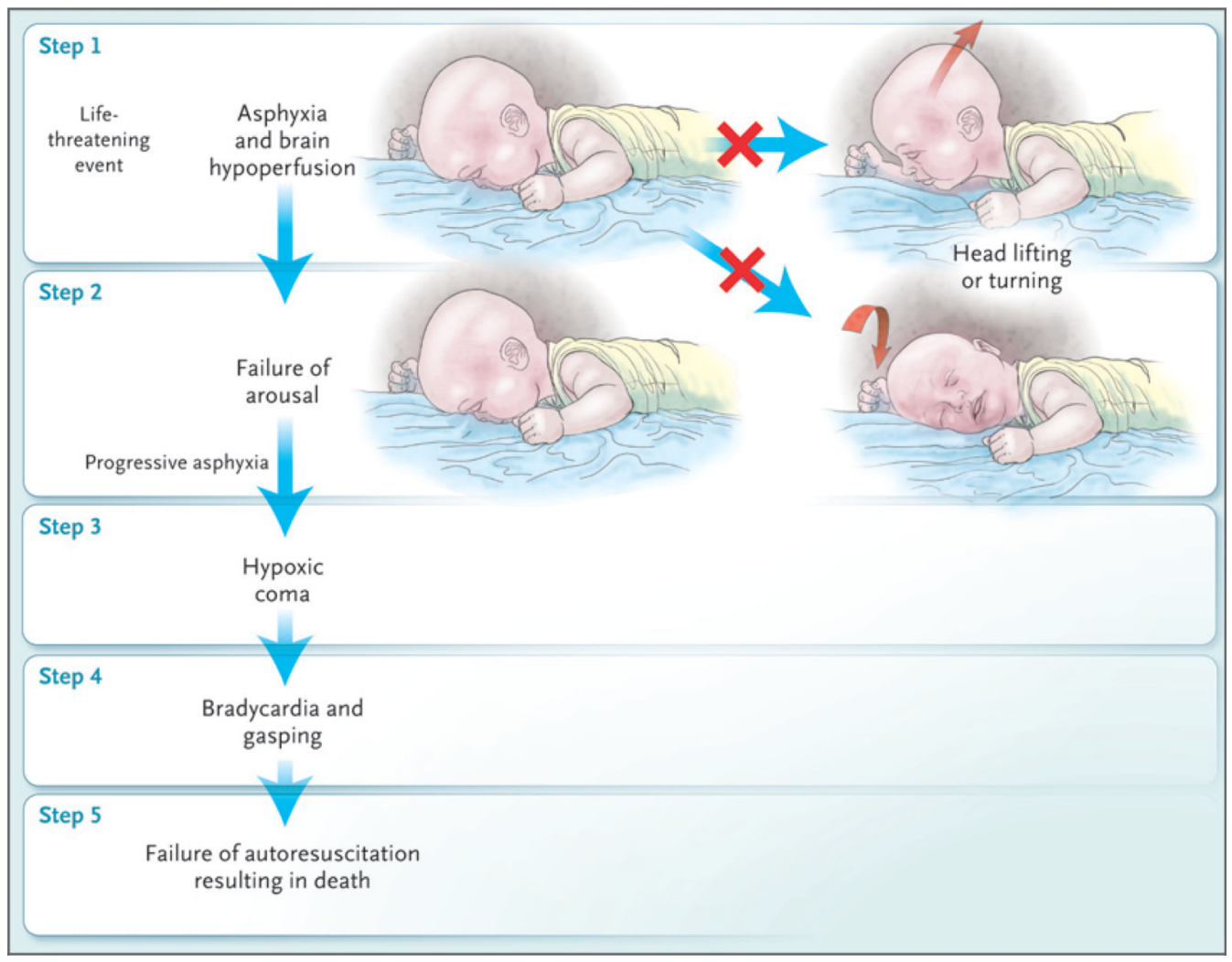

Figure 1. Five Steps in the Putative Terminal Respiratory Pathway Associated with the Sudden Infant Death Syndrome

Death results from one or more failures in protective mechanisms against a life-threatening event during sleep in the vulnerable infant during a critical period. Complex genetic and environmental interactions influence the pathway. 


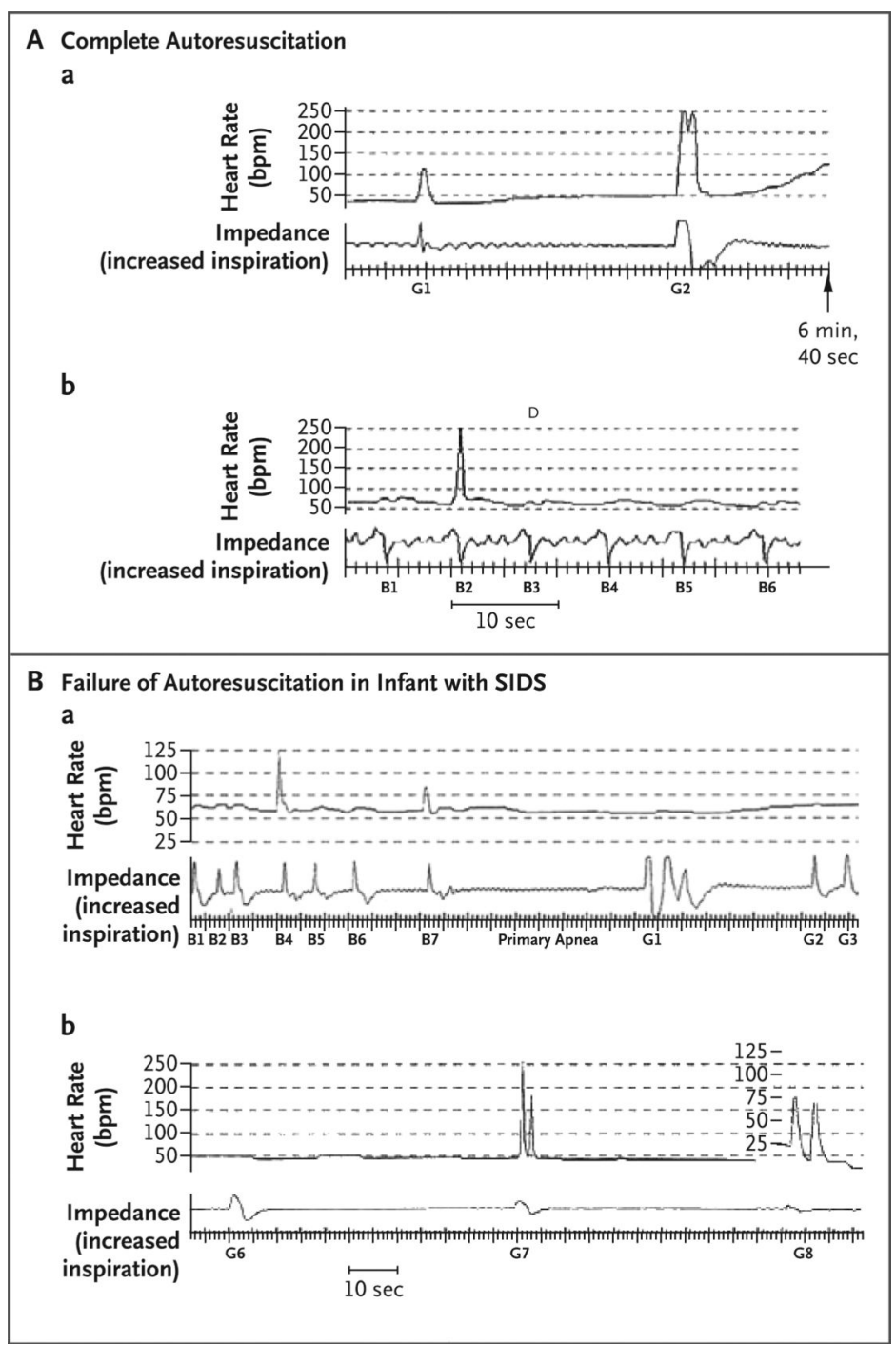

Figure 2. Cardiorespiratory Recordings in Infants, Showing the Results of Successful and Unsuccessful Autoresuscitation

Complete autoresuscitation (Panel A) is compared with ineffectual gasping (Panel B) in cardiorespiratory recordings from infants who died suddenly while being monitored at home.68 In Panel A, the tracing starts with a gasp (G1), which is followed by a gradual increase in the heart rate (subpanel a). (The spikes in heart rate that are simultaneous with gasps are probably recording artifacts.) The second gasp (G2) results in an increased heart rate, at more than 100 beats per minute. After an interruption of 6 minutes 40 seconds, eupneic breaths are noted (subpanel b). Each large breath (B1-B6) is preceded and followed by smaller breaths. Larger breaths may be sighs. In Panel B, hyperpneic breaths (B1-B7) are followed by 35 seconds of primary (hypoxic) apnea (subpanel a). Gasps (G1-G3) follow this apnea. G1 is an abnormally complex, triple gasp. A period of terminal gasps (G6-68) occurs about 10 minutes after the onset of primary apnea, with decreasing amplitude and altered configuration (subpanel b). SIDS denotes sudden infant death syndrome. 


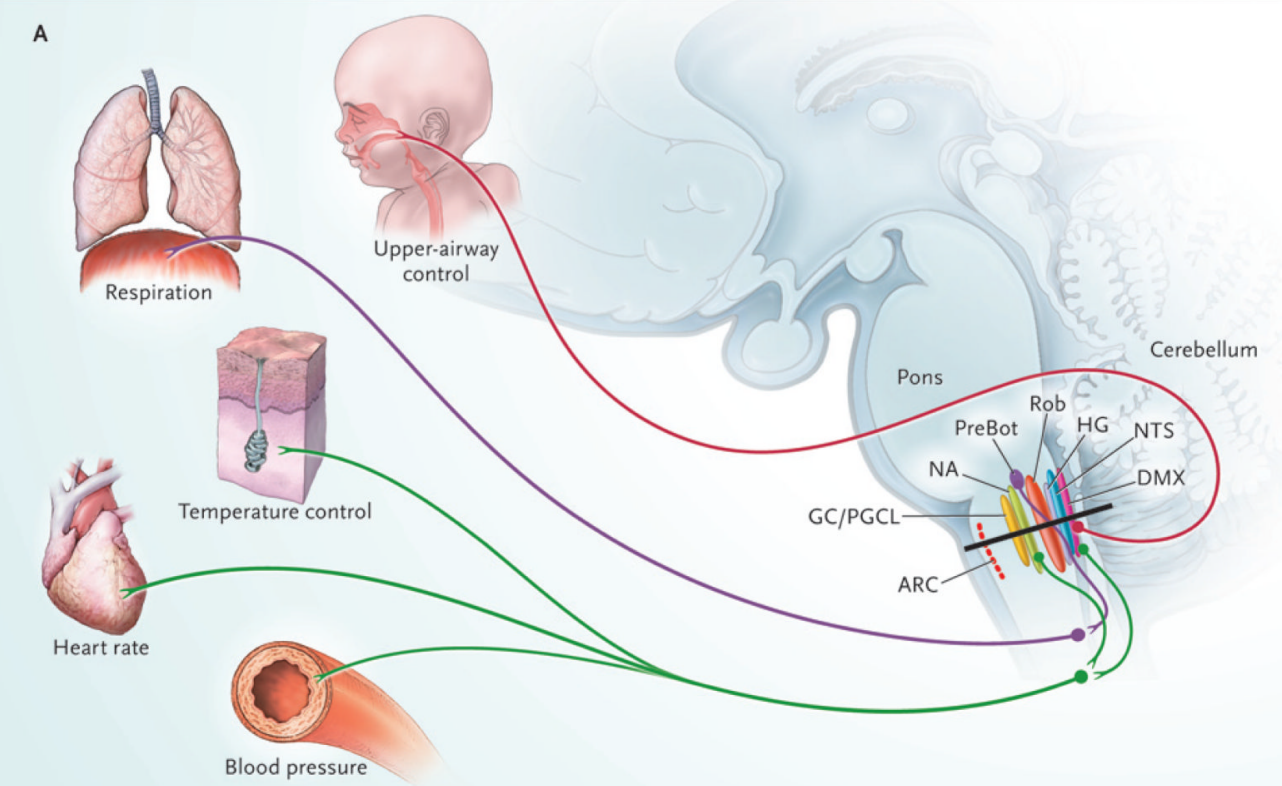

B Infant with Sudden Infant Death Syndrome
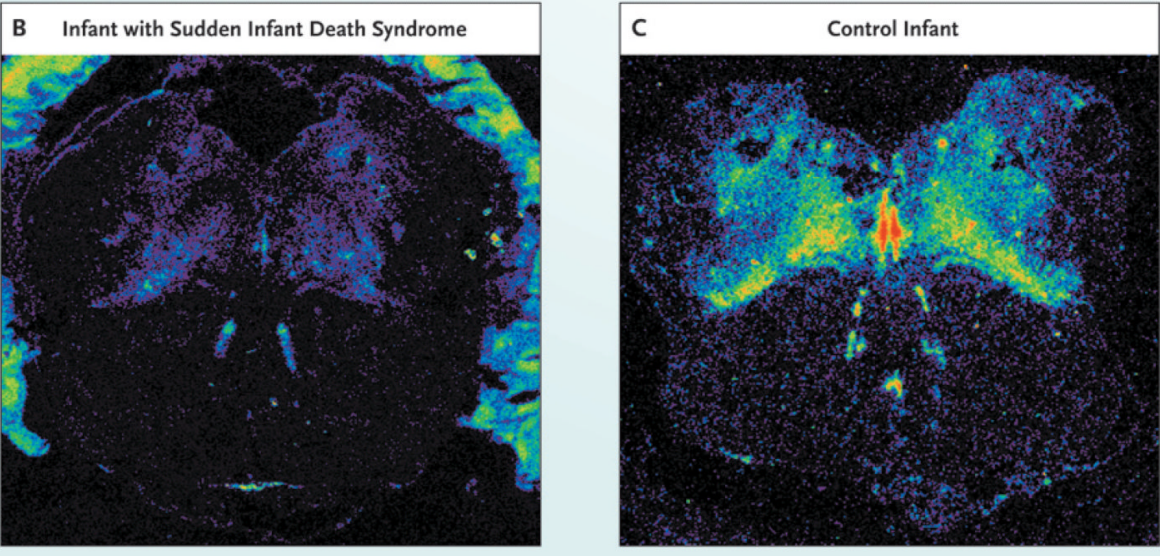

Figure 3. The Serotonergic System and Possible Effects on Homeostatic Function

The serotonergic system is considered to be critical for the modulation and integration of diverse homeostatic functions. The medullary level of the brain stem (black line in Panel A) includes regions involved in the regulation of upper-airway control, respiration, temperature, autonomic function, and the sympathetic nervous system. In the medulla of an infant with the sudden infant death syndrome (SIDS), tissue autoradiography that was performed with the use of a specific radioligand shows a generalized reduction in binding to the 5-

hydroxytryptamine type $1 \mathrm{~A}$ receptor (Panel B), as compared with that in a control infant at the same postconceptional age (Panel C). ARC denotes arcuate nucleus, DMX dorsal motor nucleus of the vagus nerve, GC ganglion cells, HG hypoglossal nucleus, NA noradrenaline, NTS nucleus tractus solitarius, PGCL paragigantocellularis lateralis, PreBot pre-Bötzinger complexes, and $\mathrm{ROb}$ raphe obscurus. Modified from a figure in Paterson et al. ${ }^{34}$ 
Table 1

Components of the Triple-Risk Model of the Sudden Infant Death Syndrome.

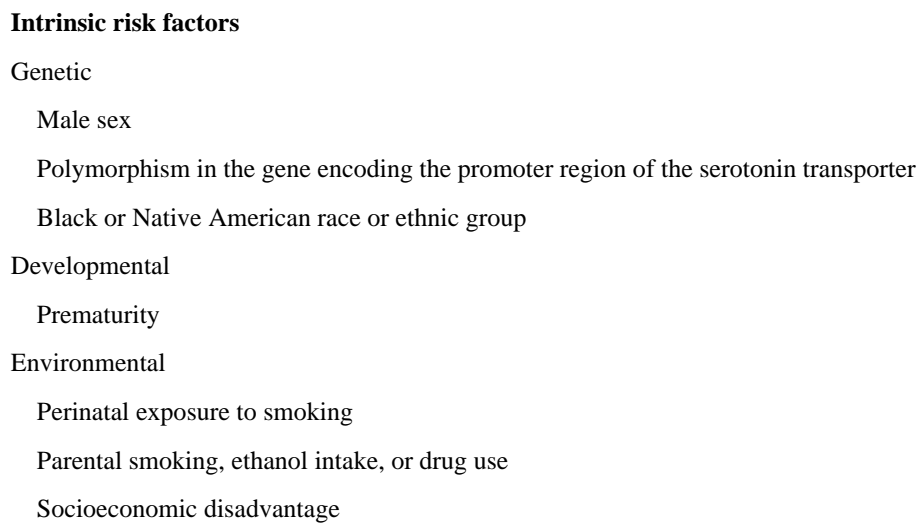

Extrinsic risk factors

Sleeping on the side or in prone position

Soft bedding

Bed sharing

Mild infections, including colds 